\title{
RIP3 overexpression sensitizes human breast cancer cells to parthenolide in vitro via intracellular ROS accumulation
}

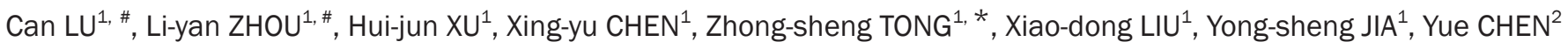 \\ ${ }^{1}$ Department of Breast Oncology, Tianjin Medical University Cancer Institute and Hospital, Key Laboratory of Breast Cancer Prevention \\ and Therapy, Tianjin Medical University, Ministry of Education, Key Laboratory of Cancer Prevention and Therapy, Tianjin 300060, \\ China; ${ }^{2}$ The State Key Laboratory of Medicinal Chemical Biology, Synergetic Innovation Center of Chemical Science and Engineering \\ (Tianjin), College of Pharmacy, and Tianjin Key Laboratory of Molecular Drug Research, Nankai University, Tianjin 300060, China
}

Aim: Receptor-interacting protein 3 (RIP3) is involved in tumor necrosis factor receptor signaling, and results in NF-kB-mediated prosurvival signaling and programmed cell death. The aim of this study was to determine whether overexpression of the RIP3 gene could sensitize human breast cancer cells to parthenolide in vitro.

Methods: The expression of RIP3 mRNA in human breast cancer cell lines (MCF-7, MDA-MB-231, MDA-MB-435 and T47D) was detected using RT-PCR. Both MDA-MB-231 and MCF-7 cells were transfected with RIP3 expression or blank vectors via lentivirus. Cell viability was measured with MTT assay; intracellular ROS level and cell apoptosis were analyzed using flow cytometry.

Results: RIP3 mRNA expression was not detected in the four human breast cancer cell lines tested. However, the transfection induced higher levels of RIP3 protein in MCF-7 and MDA-MB-231 cells. Furthermore, overexpression of RIP3 decreased the IC ${ }_{50}$ values of parthenolide from 17.6 to $12.6 \mu \mathrm{mol} / \mathrm{L}$ in MCF-7 cells, and from 16.6 to $9.9 \mu \mathrm{mol} / \mathrm{L}$ in MDA-MB-231 cells. Moreover, overexpression of RIP3 significantly increased parthenolide-induced apoptosis and ROS accumulation in MCF-7 and MDA-MB-231 cells. Pretreatment with N-acetyl-cysteine abrogated the increased sensitivity of RIP3-transfected MCF-7 and MDA-MB-231 cells to parthenolide. Conclusion: Overexpression of RIP3 sensitizes MCF-7 and MDA-MB-231 breast cancer cells to parthenolide in vitro via intracellular ROS accumulation.

Keywords: breast cancer; receptor-interacting protein 3; parthenolide; reactive oxygen species; apoptosis; N-acetyl-cysteine Acta Pharmacologica Sinica (2014) 35: 929-936; doi: 10.1038/aps.2014.31; published online 9 Jun 2014

\section{Introduction}

Receptor-interacting protein 3 (RIP3) is a Ser/Thr kinase that belongs to the RIP kinase family and was identified in $1999^{[1]}$. RIP3 contains a homologous, N-terminal kinase domain that is shared by other members of the RIP kinase family and a unique C-terminal domain ${ }^{[2]}$. It has been reported that RIP3 is involved in tumor necrosis factor receptor (TNFR) signaling, which results in nuclear factor- $\mathrm{kB}(\mathrm{NF}-\mathrm{kB})$-mediated prosurvival signaling and programmed cell death, including apoptosis and necroptosis.

RIP3 is thought to participate in the apoptotic process by selectively binding to large prodomain initiator caspases at its C-terminus ${ }^{[3]}$. RIP3 is recruited to the TNFR1 signaling com-

\footnotetext{
\# These authors contributed equally to this work.

* To whom correspondence should be addressed.

E-mail 18622221181@163.com

Received 2013-06-20 Accepted 2014-01-03
}

plex by interacting with RIP1 via its RIP homotypic interaction motif and then promotes apoptosis by activating caspases and/or inhibiting RIP- and TNFR1-induced NF-KB activation $^{[4]}$. However, the influence of RIP3 on NF- $\mathrm{KB}$ activation remains controversial. When apoptotic cell death is blocked by pan-caspase inhibitors z-VAD-fmk, the cell uses necroptosis as an alternative cell death pathway ${ }^{[5]}$. The complex containing RIP3 could function as a "necrosome" to interact with and enhance the catalytic activity of glycogen phosphorylase, glutamate-ammonia ligase and glutamate dehydrogenase 1 upon TNF- $\alpha$ and z-VAD-fmk treatment. The increased activity of those bioenergetic enzymes leads to higher energy metabolism and the subsequent enhancement of reactive oxygen species (ROS) production ${ }^{[6]}$. Therefore, RIP3 was considered as a key switch between TNF-induced necroptosis and survival ${ }^{[7]}$.

Parthenolide (PTL) is the main sesquiterpene lactone extract that is isolated from herbs such as feverfew (Tanacetum parthenium). Due to its anti-inflammatory and low toxicity proper- 
ties, PTL has been used conventionally for centuries to treat migraine and rheumatoid arthritis ${ }^{[8]}$. In recent years, the anticancer properties of PTL were discovered and attracted a great deal of therapeutic interest. PTL may induce apoptosis and inhibit the proliferation of various human cancer cells, such as colorectal cancer, hepatoma and pancreatic carcinoma, in vitro ${ }^{[8-11]}$. In addition, PTL can sensitize resistant cancer cells to antitumor agents ${ }^{[7,8,12]}$. It was reported that PTL could sensitize cancer cells to the action of drugs that induce intrinsic apoptosis ${ }^{[13]}$. The mechanism behind the antitumor activity of PTL was partially elucidated and included the inhibition of NF-KB, which causes mitochondrial dysfunction and increased ROS level ${ }^{[14,15]}$. However, the detailed and precise mechanism underlying PTL-induced apoptosis remains largely unclear.

Breast cancer is one of the main causes of death from cancer in women. Cancer-induced death is generally due to metastasis and the development of resistance to chemotherapy. PTL and its sesquiterpene lactone analogues might be new chemotherapeutic agents for breast cancer.

In this study, we explored the impact of RIP3 expression restoration on the sensitivity of RIP3-deficient breast cancer cell lines to PTL and studied the mechanisms by which cell death was induced.

\section{Materials and methods Cell culture and reagents}

The human breast cancer cell lines (MCF-7, MDA-MB-231, MDA-MB-435 and T47D) and the human mammary epithelial cell line (MCF-10A) were preserved by our laboratory. The human breast cancer cell lines were cultured in Dulbecco's modified Eagle's medium (DMEM; HyClone, Logan, Utah, USA) containing 10\% fetal bovine serum (Gibco, Grand Island, NY, USA) and $1 \%$ penicillin/streptomycin mixture at $37^{\circ} \mathrm{C}$ in a humidified atmosphere of $5 \% \mathrm{CO}_{2}$ and $95 \%$ air. MCF-10A cells were maintained in DMEM/F12 (Invitrogen, Carlsbad, CA, USA) containing 5\% horse serum (Invitrogen), epidermal growth factor (EGF; $100 \mathrm{mg} / \mathrm{mL})$, hydrocortisone $(1 \mathrm{mg} / \mathrm{mL})$, cholera toxin $(1 \mathrm{mg} / \mathrm{mL})$, insulin $(10 \mathrm{mg} / \mathrm{mL})$ and $1 \%$ penicillin/streptomycin at $37^{\circ} \mathrm{C}$ in a humidified atmosphere of $5 \%$ $\mathrm{CO}_{2}$ and $95 \%$ air. PTL (kindly given by Nankai University Pharmaceutical College) was supplied as a crystalline solid, dissolved in dimethylsulfoxide (DMSO; $100 \mathrm{mmol} / \mathrm{L}$ stock; Sigma, St Louis, MO, USA), and stored at $-20^{\circ} \mathrm{C}$. The RIP3 antibody was purchased from Santa Cruz Biotechnology (Santa Cruz, CA, USA), and the PARP antibody and $\beta$-actin antibody were obtained from Cell Signaling Technology (Boston, CA, USA).

\section{Measurement of mRNA levels in different wild type breast cancer} cell lines

Total RNA was isolated using TRIzol reagent (Invitrogen) according to the manufacturer's instructions. Reverse transcription polymerase chain reaction (RT-PCR) was performed to measure the RIP3 mRNA levels in different cell lines (MCF7, MDA-MB-231, MDA-MB-435, T47D and MCF-10A), and GAPDH was used as an internal control. RT-PCR analysis was performed using a one-step RT-PCR kit (Bio Shinegene Inc, Shanghai, China) and the following primers: GAPDH forward 5'-GAAGGTGAAGGTCGGAGTC-3' and reverse 5'-GAA GATGGTGATGGGATTTC-3'. RT-PCR analysis was performed at $95^{\circ} \mathrm{C}$ for $5 \mathrm{~min}$, then with 30 cycles of $95^{\circ} \mathrm{C}$ for $5 \mathrm{~s}$, $65.5^{\circ} \mathrm{C}$ for $30 \mathrm{~s}, 72^{\circ} \mathrm{C}$ for $30 \mathrm{~s}$ and $72^{\circ} \mathrm{C}$ for $10 \mathrm{~min}$. An aliquot $(5 \mu \mathrm{L})$ of the RT-PCR product was subjected to electrophoresis in a $1 \%$ agarose gel.

\section{Generation of stable cell lines}

The RIP3 cassette was amplified using PCR from the RIP3 expression plasmid which was graciously provided by Professor Han Jia-huai, Institute of Life Science, Xiamen University (primer sequences: forward 5'-TGTACAAGTCTAGAGCTAGCATGTCGTGCGTCAAGTTA-3', reverse 5'-CGCGGCCGCGGATCCTTATTTCCCGCTATGATT-3'), and the segment was inserted into a lentiviral vector using the E-Fusion Cloning Kit (Biophay Biotechnology Co, Huaian, China). The vector carried a blasticidin resistance marker and a red fluorescent protein and was preserved by our laboratory. The plasmids were subsequently purified and sequenced. Lentivirus particles were produced using transient cotransfection of the RIP3 expression vector and packaging vectors (VSVG and $\triangle \mathrm{R}$ ) into 293 T cells using the calcium phosphate transfection method. Viral particles containing control empty vector were similarly prepared. The cell supernatant was harvested $48 \mathrm{~h}$ later and mixed with a lentivirus concentration solution (volume ratio 4:1) followed by incubation at $4{ }^{\circ} \mathrm{C}$ for at least $1 \mathrm{~h}$. Then, the supernatant was centrifuged at a speed of 6000 rounds/min, and the lentivirus was resuspended in cell culture medium and incubated in wells containing MCF-7 or MDA-MB-231 cells. The cells were treated with $4 \mathrm{mg} / \mathrm{L}$ blasticidin and tested for expression of the transgene one week later.

\section{MTT colorimetric survival assay}

MCF-7 and MDA-MB-231 cells were plated at a density of $0.8 \times 10^{4}$ cells per well in 96 -well plates. After 24 -h incubation, the cells were treated with PTL at the indicated concentrations for $48 \mathrm{~h}$, the medium was removed, and $200 \mu \mathrm{L}$ of fresh medium plus $20 \mu \mathrm{L}$ of 3-(4,5-dimethylthiazol-2-yl)-2,5-diphenyltetrazolium bromide (MTT, $50 \mathrm{~g} / \mathrm{L}$ dissolved in DMSO) was added to each well. After incubation for $4 \mathrm{~h}$ at $37^{\circ} \mathrm{C}$, the culture medium containing MTT was withdrawn, and $200 \mu \mathrm{L}$ of DMSO was added followed by shaking for $10 \mathrm{~min}$ until the crystals were dissolved. Viable cells were detected by measuring the absorbance at $570 \mathrm{~nm}$ using an MRX II absorbance reader (DYNEX Technologies, Chantilly, VA, USA). The cell growth was expressed as the ratio of absorbance of cells exposed to the PTL treatment to that of cells not exposed to the treatment $(100 \%)$. The inhibition rate (IR) was calculated as follows: $\% \mathrm{IR}=(1-\mathrm{absorbance}$ value of PTL well/absorbance value of control well) $\times 100$.

\section{Western blot analysis}

For Western blot analysis, the cells were washed three times with PBS, homogenized in cell lysis buffer, incubated on ice 
for $20 \mathrm{~min}$, and then centrifuged for $15 \mathrm{~min}$ at 10000 rounds/min. The aqueous supernatant was collected and quantified using a BCA protein assay kit (Boster, Wuhan, China). Equal amounts $(30 \mu \mathrm{g})$ of protein extract were loaded and separated using SDS polyacrylamide gel electrophoresis. After electrophoresis, the proteins on the gel were transferred to a PVDF membrane and incubated with the corresponding antibodies. The immune complexes were detected using the LI-COR Odyssey infrared imaging system (Li-Cor, Lincoln, NE, USA).

\section{Observation of morphologic changes}

MCF-7 and MDA-MB-231 cells $\left(3 \times 10^{5} /\right.$ well) were seeded into 6-well culture plates. After $24 \mathrm{~h}$ of incubation, the cells were treated with or without PTL for $48 \mathrm{~h}$, and the cellular morphology was observed using a Nikon Eclipse TE2000-U inverted microscope coupled to a Digital-Sight DS-2Mv digital camera (Nikon, Sendai, Japan).

\section{Observation of nuclear damage using Hoechst 33342 staining} MCF-7 and MDA-MB-231 cells $\left(3 \times 10^{5} /\right.$ well) were cultured in 6-well culture plates. After $24 \mathrm{~h}$ of incubation, the cells were treated with or without $25 \mu \mathrm{mol} / \mathrm{L}$ PTL for $24 \mathrm{~h}$. The cells were then incubated with $10 \mu \mathrm{g} / \mathrm{L}$ Hoechst 33342 dye at $37^{\circ} \mathrm{C}$ for $30 \mathrm{~min}$, and the nuclear changes in fluorescence were observed using an OLYMPUS IX70 reverse fluorescence microscope (Olympus, Tokyo, Japan) at an excitation wavelength of $350 \mathrm{~nm}$ and emission filter of $460 \mathrm{~nm}$.

\section{Analysis of apoptosis by flow cytometry}

Cells $\left(3 \times 10^{5}\right)$ suspended in $2 \mathrm{~mL}$ of fresh media were plated into each well of a 6-well, flat-bottomed microtiter plate and incubated overnight. Then, the cells were treated with or without $12.5 \mathrm{\mu mol} / \mathrm{L}$ PTL for $48 \mathrm{~h}$. After being harvested, the cells were washed twice with pre-chilled PBS and then resuspended in $1 \times$ binding buffer at a concentration of $1 \times 10^{6}$ cells $/ \mathrm{mL}$. The solution $\left(100 \mu \mathrm{L}, 1 \times 10^{5}\right.$ cells $)$ was then mixed with $5 \mu \mathrm{L}$ of Annexin V-FITC and $5 \mu \mathrm{L}$ of propidiumiodide (BD Biosciences, San Jose, CA, USA) according to the manufacturer's instruction. The mixed solution was incubated at room temperature away from light for $15 \mathrm{~min}$, and then $400 \mu \mathrm{L}$ of $1 \times$ dilution buffer was added to each tube. Analysis was performed using a FACScan flow cytometer within $1 \mathrm{~h}$.

\section{Flow cytometric analysis of intracellular ROS production}

Cells $\left(3 \times 10^{5}\right)$ suspended in $2 \mathrm{~mL}$ of fresh media were plated in each well of a 6-well, flat-bottomed microtiter plate and incubated overnight, and the cells were treated with or without $12.5 \mathrm{mmol} / \mathrm{L}$ PTL for $4 \mathrm{~h}$. Then, the cells were incubated with $10 \mu \mathrm{mol} / \mathrm{L}$ DCF-DA at $37^{\circ} \mathrm{C}$ for $15 \mathrm{~min}$ to assess the ROSmediated oxidation of DCF-DA to the fluorescent compound DCF. Next, the cells were harvested, and the pellets were suspended in $1 \mathrm{~mL}$ PBS. Samples were analyzed at an excitation wavelength of $480 \mathrm{~nm}$ and an emission wavelength of $525 \mathrm{~nm}$ using a FACScan flow cytometer (Becton-Dickinson, Franklin Lakes, NJ, USA).

\section{Statistical analysis}

All experiments were performed at least three times. Excel (Microsoft, Redmond, WA, USA) was used for statistical analysis, and statistical significance was determined using Student's $t$-test. $P<0.05$ was considered significant.

\section{Results}

The RIP3 expression level in different wild type breast cancer cell lines and RIP3-MCF-7/MDA-MB-231 cells

We performed RT-PCR analysis of the RIP3 mRNA in different cell lines (MCF-7, MDA-MB-231, MDA-MB-435, T47D and MCF-10A). The results showed the universal lack of mRNA expression of RIP3 in these breast cancer cell lines compared with the human mammary epithelial cell line MCF-10A (Figure 1A). We decided to work with MCF-7 and MDA-MB-231 cells, which expressed low concentrations of RIP3. We transducted those cells with an expression vector for RIP3 or a control empty vector. Using RT-PCR and Western blotting, we confirmed that RIP3-MCF-7/MDA-MB-231 cells highly expressed RIP3 at the mRNA and protein levels (Figure 1B and $1 \mathrm{C})$. Using fluorescence microscopy, we confirmed the high gene transduction efficiency of RIP3 in MCF-7 and MDAMB-231 cells, and observed diffuse cytoplasmic distribution of exogenous RIP3 in both cell lines (Figure 1D).

\section{Survival of MCF-7 and MDA-MB-231 cells in response to PTL is} decreased when RIP3 is expressed

We examined the cytotoxic effects of PTL against MCF-7 and MDA-MB-231 cells treated with various concentrations (0-25 $\mu \mathrm{mol} / \mathrm{L}$ ) of PTL for $48 \mathrm{~h}$, and the number of surviving cells was quantitatively determined using the MTT assay (Figure 2). PTL treatment significantly decreased cell viability in a dose-dependent manner. To determine how RIP3 expression affected the sensitivity of MCF-7 and MDA-MB-231 cells to PTL-induced cell death, the cells were treated with PTL in the same manner as metioned above, and the survival rate was relative to that of untreated cells. Overexpression of RIP3 reduced the half maximal inhibitory concentration value of PTL from 17.6 to $12.6 \mu \mathrm{mol} / \mathrm{L}$ in MCF-7 cells and from 16.6 to $9.9 \mu \mathrm{mol} / \mathrm{L}$ in MDA-MB-231 cells. The most obvious sensitivity effect was observed at the concentration of $12.5 \mu \mathrm{mol} / \mathrm{L}$ for both cell lines. These results showed that MCF-7 and MDAMB-231 cells overexpressing RIP3 were more sensitive to PTL than their parental, RIP3-defective counterparts.

\section{RIP3 sensitizes MCF-7 and MDA-MB-231 cells to PTL-induced} apoptosis

PTL has been reported to inhibit cell growth and induce apoptosis in a variety of tumor cells, and RIP3 overexpression is a known trigger of apoptosis. To explore whether RIP3-MCF-7/ MDA-MB-231 cells were more sensitive to PTL-induced apoptosis than control cells, control and RIP3-MCF-7/MDAMB-231 cells treated with $12.5 \mu \mathrm{mol} / \mathrm{L}$ PTL for $48 \mathrm{~h}$ were stained by phosphatidylserine exposure to Annexin V-FITC and analyzed using flow cytometry. The results showed that 
A

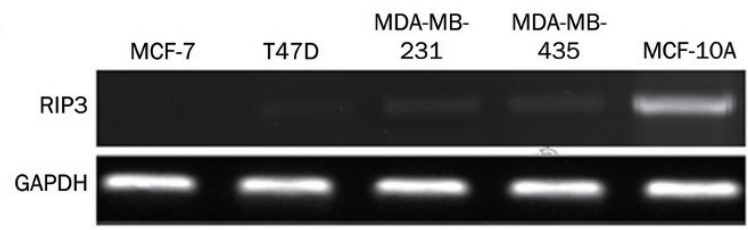

B

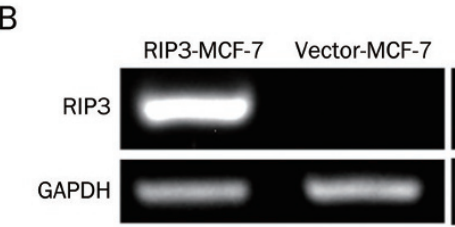

C

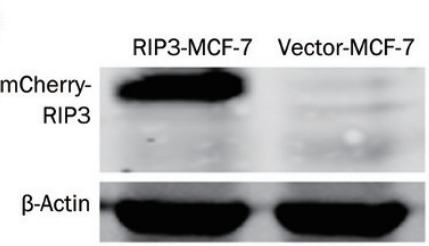

D
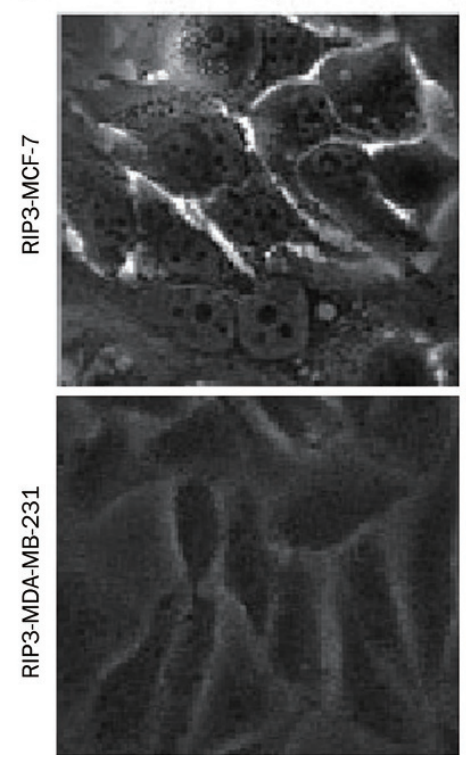

RIP3-MDA- Vector-MDAMB-231 MB-231
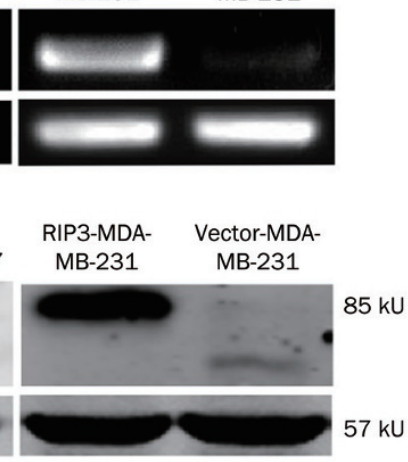

b
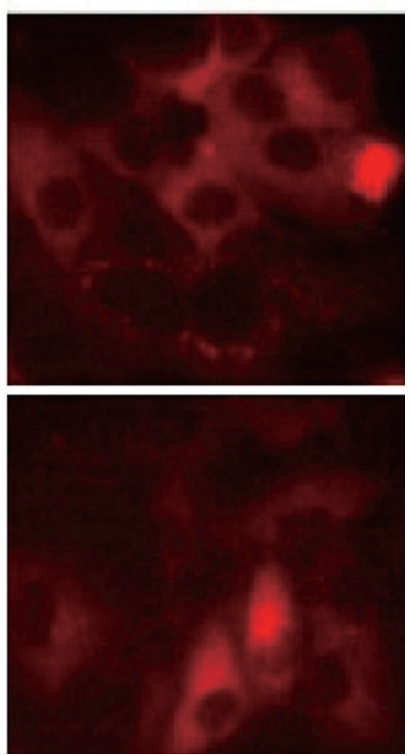

Figure 1. (A) Expression of RIP3 mRNA in different breast cell lines was determined by RT-PCR. Products of RT-PCR were analyzed by agarose gel elecrophoresis. GAPDH was used as internal control. (B) RIP3 mRNA expressions in MCF-7 and MDA-MB-231 cells were detected by RT-PCR. GAPDH was used as internal control. (C) RIP3 protein expressions in MCF-7 and MDA-MB-231 cells were detected by Western blotting. $\beta$-Actin was used as loading control. RIP3 mRNA and protein expression considerably increased in RIP3-MCF-7/MDA-MB-231 cells compared with vector-MCF-7/MDA-MB-231 cells. (D) RIP3 expression and cellular distribution were observed by fluorescent microscope. (a) Light microscope, (b) fluorescence microscope ( $\times 200$ magnification).

PTL induced an increase in Annexin- $\mathrm{V}$ fluorescence from $6.2 \%$ in control cells to $29.2 \%$ in MCF-7 cells and from $9.7 \%$ in control cells to $17.9 \%$ in MDA-MB-231 cells ${ }^{[1,2,15,16]}$, and RIP3 overexpression with cotreatment of PTL resulted in an
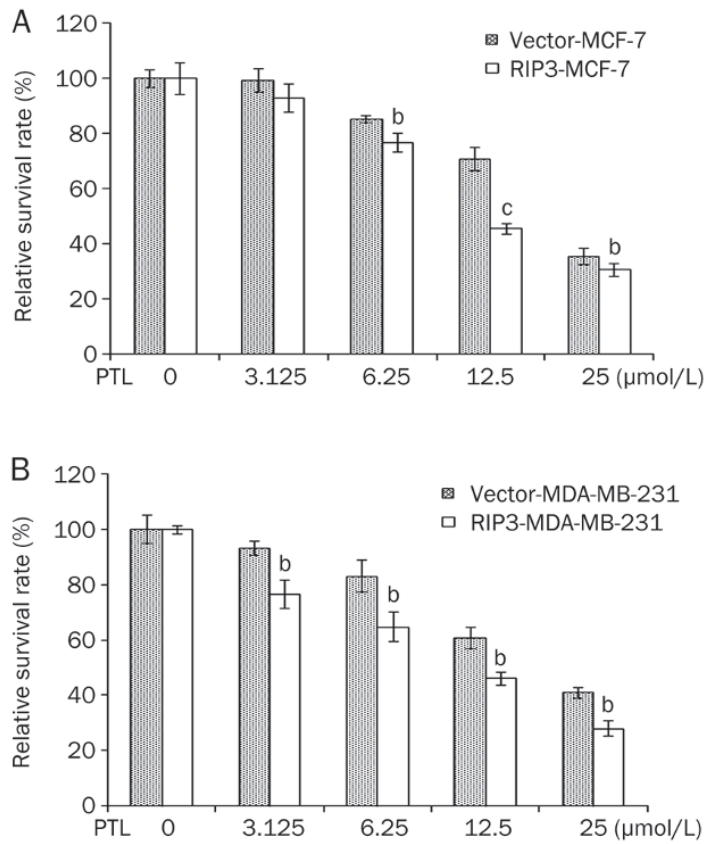

Figure 2. RIP3 overexpression enhance the PTL's inhibition of MCF-7 and MDA-MB-231 cells proliferation. Cell viability was determined by MTT assay. The cell survival rates were calculated by comparing with the control group (100\%) after $48 \mathrm{~h}$ treatment. Data were presented as the mean $\pm S D(n=4)$. ${ }^{b} P<0.05,{ }^{c} P<0.01$ compared with vector infected group.

increase from $29.2 \%$ to $37.7 \%$ in MCF-7 cells and from $17.9 \%$ to 27.5\% in MDA-MB-231 cells with PTL treatment only (Figure 3A). These findings indicate that MCF-7 and MDA-MB-231 cells expressing higher RIP3 levels are more sensitive to PTLinduced cell death.

In addition, morphological changes were observed in control and RIP3-MCF-7/MDA-MB-231 cells after incubation with various concentrations of PTL for $48 \mathrm{~h}$. As illustrated in Figure 3B, after PTL treatment a higher proportion of RIP3-MCF-7/ MDA-MB-231 cells exhibited distinctly shrinked and rounded shapes compared with control cells. To further explore whether the morphological changes that were induced by PTL were accompanied by nuclear changes, we fixed and stained control and RIP3-MCF-7/MDA-MB-231 cells that were treated with $25 \mu \mathrm{mol} / \mathrm{L}$ of PTL for $24 \mathrm{~h}$ with Hoechst 33342 and examined their nuclear patterns using fluorescence microscopy. The nuclei of RIP3-MCF-7/MDA-MB-231 cells exhibited more chromosome condensation and fragmentation (Figure 3C).

Apoptosis induction was also detected using Western blotting, which showed the cleavage of PARP. No PARP cleavage was observed in untreated cells, and the addition of PTL to the vector-cells did not substantially enhance this effect. However, we observed PARP cleavage following PTL treatment in RIP3-MCF-7/MDA-MB-231 cells (Figure 3D).

\section{Overexpression of RIP3 increases superoxide production after} PTL treatment

Oxidative stress has been shown to be a major mechanism for 
A

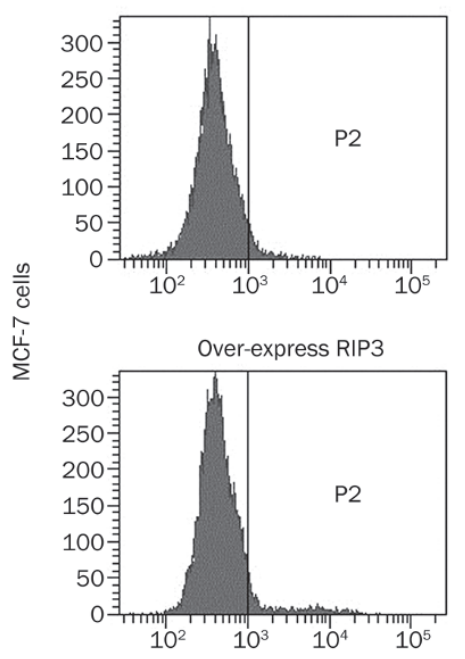

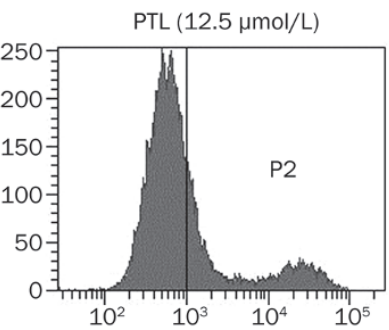
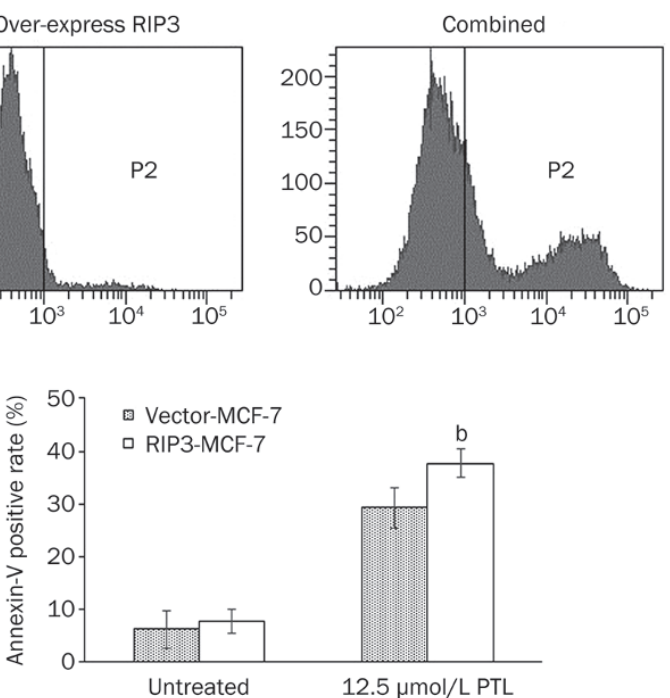
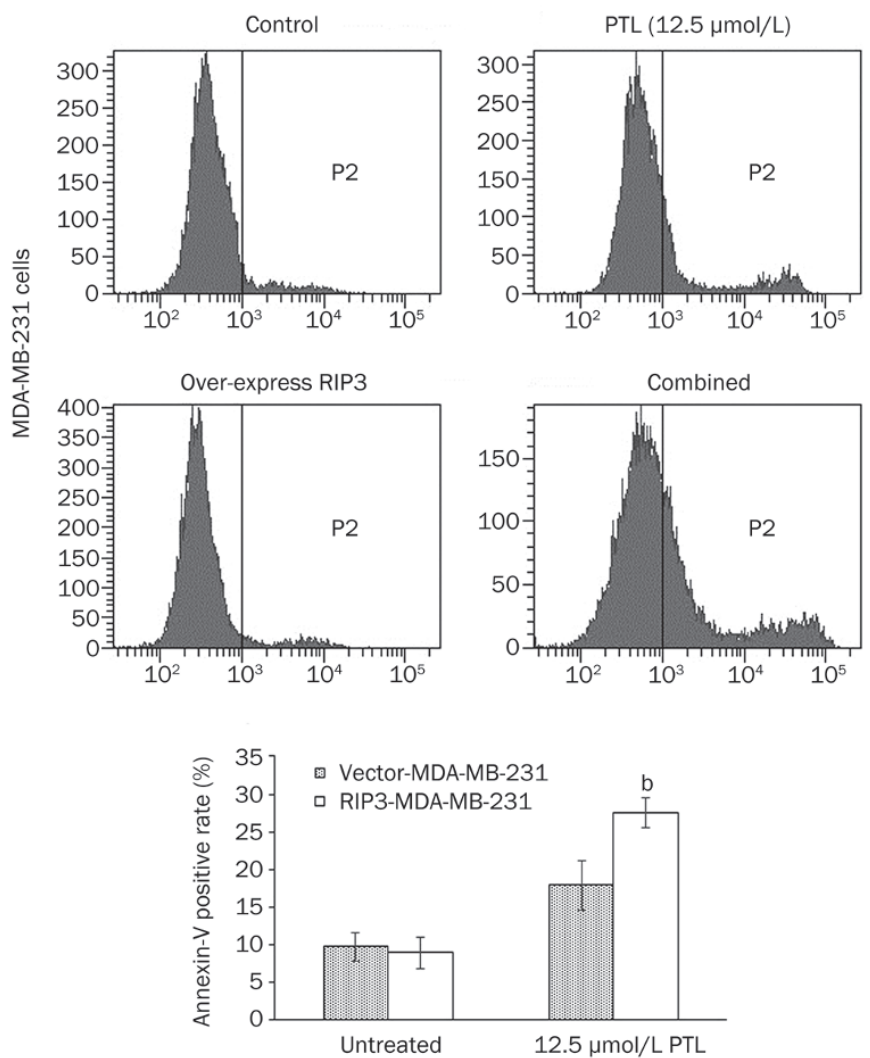

Figure 3A. PTL induced apoptosis in MCF-7 and MDA-MB-231 cells. (A) The RIP3-MCF-7/MDA-MB-231 cells and control cells were treated with 12.5 $\mu \mathrm{mol} / \mathrm{L}$ PTL for $48 \mathrm{~h}$, stained by phosphatidylserine exposure with Annexin V-FITC antibody and analyzed by FACS. Combined results of three separate FACS analysis depicting the mean levels of apoptotic cells (Annexin-V $\mathrm{V}^{+}$). PTL-treated RIP3-MCF-7 cells showed an increase in apoptosis over vectorMCF-7 controls. So did the RIP3-MDA-MB-231 cells. Data are expressed as the mean \pm SEM $(n=3)$. ${ }^{\mathrm{b}} P<0.05$ compared with vector infected group.

PTL-induced cell death. Thus, we decided to verify whether the PTL-induced ROS levels could be influenced by the overexpression of RIP3. We compared the ROS levels in control and RIP3-MCF-7/MDA-MB-231 cells exposed to $12.5 \mu \mathrm{mol} / \mathrm{L}$ PTL by simultaneously measuring the intracellular ROS levels with a specific ROS-detecting fluorescent dye, DCF-DA, used in flow cytometry (Figure 4). However, when the endogenous ROS levels were compared, the ROS level was higher in RIP3 cells than in control cells. After being treated with PTL for 4 h, RIP3-MCF-7/MDA-MB-231 cells produced significantly higher level of ROS than their corresponding vector-infected cells. Therefore, RIP3 overexpression might potentiate PTLinduced ROS accumulation following apoptosis with the PTL concentration of $12.5 \mu \mathrm{mol} / \mathrm{L}$.

ROS-mediated, RIP3 overexpression-induced PTL sensitivity in MCF-7 and MDA-MB-231 cells

To evaluate the role of ROS in the RIP3 overexpressioninduced PTL sensitivity of MCF-7 and MDA-MB-231 cells, we pretreated cells with N-acetyl-L-cysteine (NAC), the ROS scavenger, before PTL administration. PTL treatment induced apoptotic changes such as membrane blebbing and granular apoptotic bodies. In contrast, these apoptotic morphologic alterations were nearly completely suppressed by pretreat- ment with NAC. The MTT assay also demonstrated that NAC treatment significantly reduced the growth inhibition ratio of control and RIP3-MCF-7 cells from 29.9\% and 49.4\% (12.5 $\mu \mathrm{mol} / \mathrm{L}$ of PTL alone) to $19.5 \%$ and $20.7 \%$ (in the presence of $5 \mathrm{mmol} / \mathrm{L}$ of NAC), respectively. A similar phenomenon was observed for MDA-MB-231 cells (Figure 5). No significant difference between the PTL sensitivity of the control and RIP3MCF-7/RIP3-MDA-MB-231 cells was observed after cotreatment with NAC, which indicated that ROS may mediate RIP3 overexpression-induced PTL sensitivity.

\section{Discussion}

In this study, we demonstrated that overexpressing RIP3 in RIP3-deficient MCF-7 and MDA-MB-231 cells significantly increased their sensitivity to PTL-induced apoptosis and intracellular superoxide production. In addition, RIP3 overexpression-induced PTL sensitivity was weakened when the cells were pretreated with the ROS scavenger NAC.

We found that RIP3 was expressed at low levels in breast cancer cell lines, including MCF-7, MDA-MB-231, MDAMB-435 and T47D cells. RIP3-expressed MCF-7 and MDAMB-231 cells were obtained with transfection of the PCDHmCherry-RIP3 construct into cells followed by antibiotic selection of the RIP3-expressed clones for at least two weeks. 
B
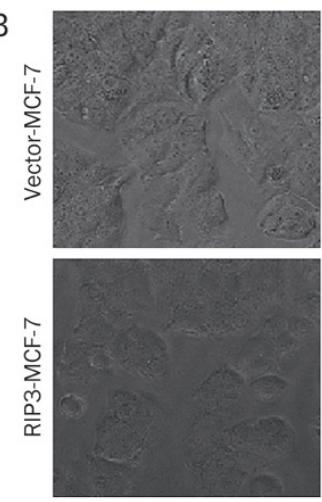

C
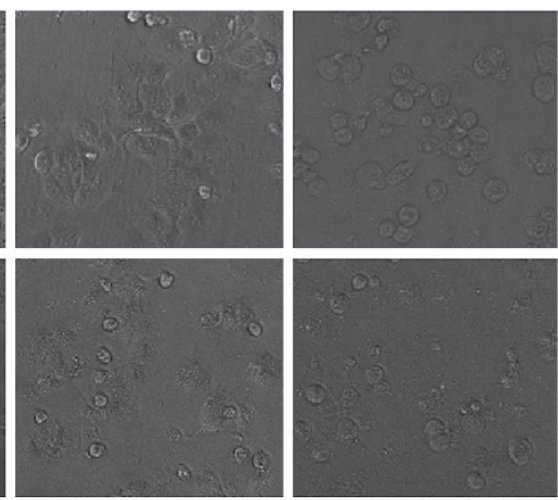

Vector
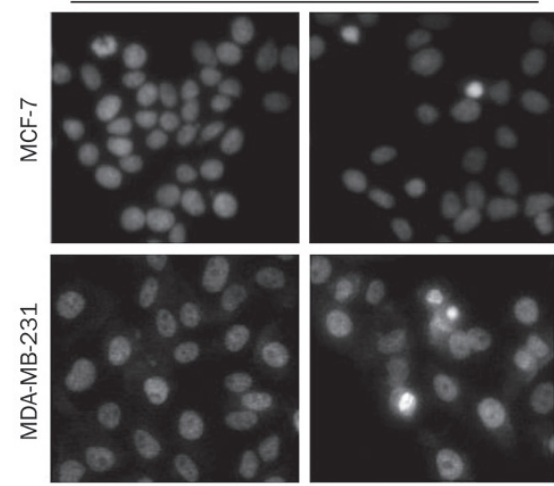

PTL

$(\mu \mathrm{mol} / \mathrm{L})$

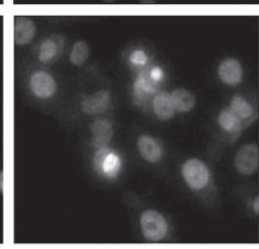

25
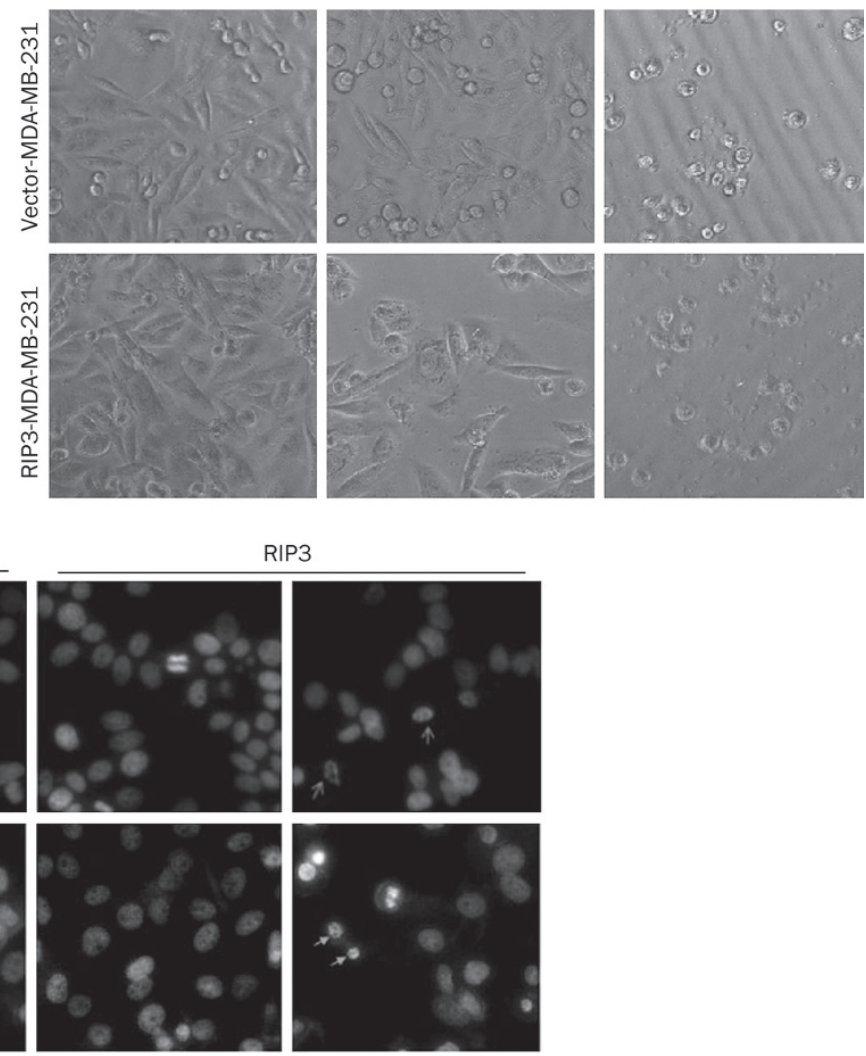

25

Figure 3B-3D. PTL induced apoptosis in MCF-7 and MDA-MB-231 cells. (B) The RIP3-MCF7/231 cells and vector-MCF-7/MDA-MB-231 cells were treated with 12.5 and $25 \mu \mathrm{mol} / \mathrm{L}$ PTL for $48 \mathrm{~h}$, the cellular morphologic changes were observed by phase contrast microscope ( $\times 200 \mathrm{magnification})$. (C) The RIP3-MCF-7/MDA-MB-231 cells and control cells were treated with $25 \mu \mathrm{mol} / \mathrm{L}$ PTL for $24 \mathrm{~h}$ and the changes in cellular morphology were observed by fluorescence microscope with Hoechst 3342 staining ( $\times 400$ magnification). (D) Western blot analysis of lysates from vector or RIP3 transfected MCF-7 and MDA-MB-231cells, followed by treatment with $12.5 \mu \mathrm{mol} / \mathrm{L}$ PTL for $24 \mathrm{~h}$. An antibody recognizing PARP was used with $\beta$-actin as a loading control. PTL treatment induced PARP cleavage in RIP3 overexpressing MCF-7 and MDA-MB-231 cells but did not induce PARP cleavage in wild type MCF-7 and MDA-MB-231 cells.

PTL has been extensively studied in relation to its anticancer properties and was shown in vitro to induce apoptosis in various human cancers ${ }^{[16,17]}$. In our study, survival tests for control and RIP3-overexpressed cells after PTL treatment were performed. We observed lower survival in RIP3-overexpressed cells, and rare differential sensitivity to chemotherapy between RIP3-deficient and RIP3-overexpressed cells ${ }^{[18]}$. This experiment also proved that RIP3 sensitized MCF-7 and MDAMB-231 cells to PTL-induced apoptosis. Contrary to the report that RIP3 overexpression could induce apoptosis ${ }^{[19-21]}$, we did not observe any spontaneous apoptosis in our RIP3-MCF-7 or RIP3-MDA-MB-231 cells. This may be because previous work studied apoptosis as soon as $24 \mathrm{~h}$ after transient transfection of the RIP3 constructs, while we tested the cells after one-week antibiotic selection. During selection, cells that did not express the transgene were killed by the antibiotic treatment, and those expressing it over a lethal level died through apoptosis pathway, which leave us with MCF-7 and MDA-MB-231 cells expressing RIP3 at a viable level that is most likely closer to the physiological level. This suggests that RIP3 actively par- ticipates in the regulation of the apoptotic pathway. However, the pathway of RIP3 mediated apoptosis has not been clearly elucidated. Furthermore, the influence of RIP3 on NF-KB, an inhibitor of apoptosis ${ }^{[22-24]}$, is controversial. In some studies, NF-KB appears to be induced by RIP3 overexpression ${ }^{[25,26]}$, but in other studies, RIP3 has no effect on its activation, but rather, acts by attenuating RIP1 and TNFR1-mediated NF-KB activation $^{[27]}$. In any case, PTL could inhibit NF-KB indirectly by blocking IKK- $\beta$ at cys179 and directly by inhibiting p65 at the cysteine residue in its activation loop, which would contribute to its apoptosis-inducing ability ${ }^{[28]}$.

PTL-induced apoptosis is also associated with increased ROS level in tumor cells because of the activation of NADPH oxidase and reduction of the cysteine group of the antioxidant, non-protein molecule glutathione ${ }^{[22,23]}$. ROS are ions or small molecules that include singlet oxygen molecules, free radicals and peroxides and are formed as byproducts of the normal cellular metabolism of oxygen ${ }^{[24]}$. The dramatic increase in ROS levels and the disruption of the antioxidant balance result in oxidative damage to cellular structures, signal transduction 
A

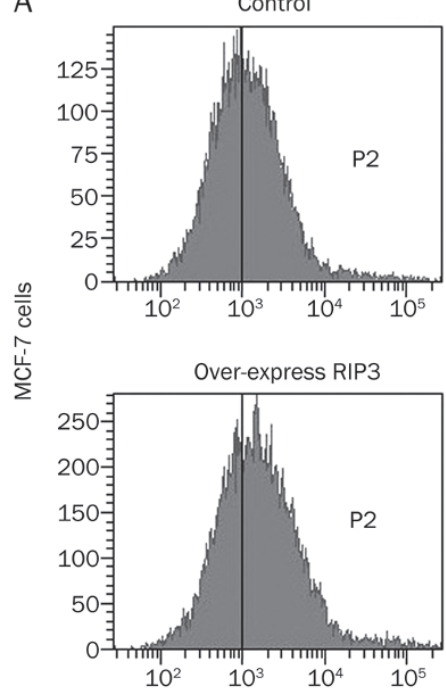

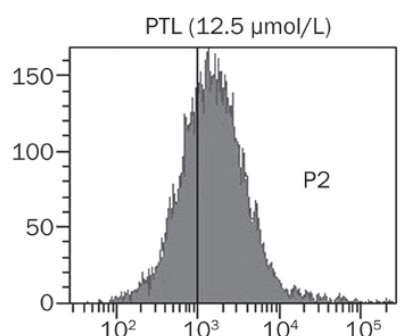

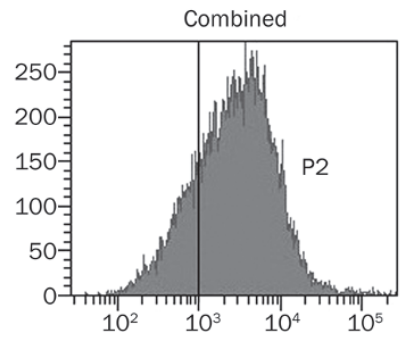

B

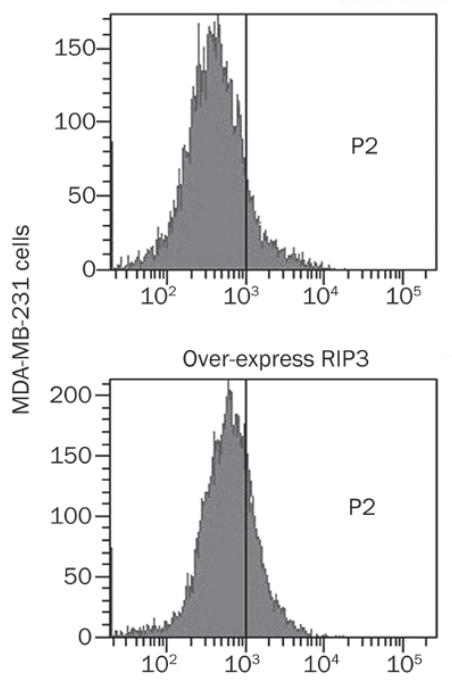

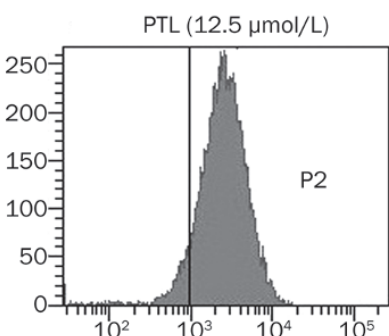

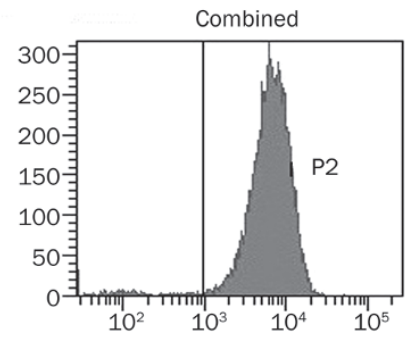

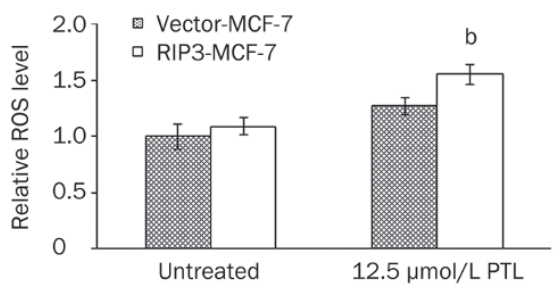

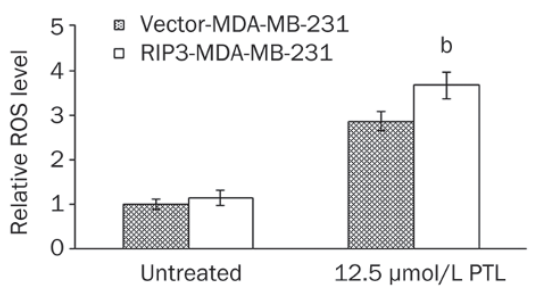

Figure 4. ROS production was induced by PTL and could be enhanced by RIP3 overexpression in MCF- 7 and MDA-MB- 231 cells. The cells were treated with $12.5 \mu \mathrm{mol} / \mathrm{L}$ PTL for $4 \mathrm{~h}$. The DCF-positive cells were measured by flow cytometry. The relative ROS level was defined as the measured ROS level relative to the untreated vector-transfected cells, which was set to 1 . Mean increase in ROS-positive cells is shown for three separate experiments. Mean \pm SD. $n=3$. ${ }^{b} P<0.05$ compared with vector infected group.
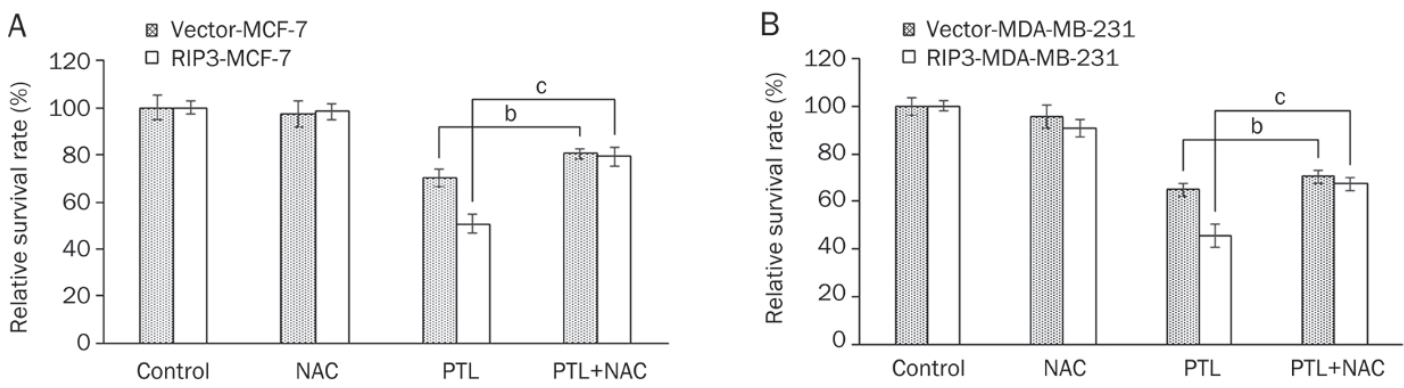

Figure 5. Effect of NAC on PTL-induced apoptosis in vector-MCF-7/MDA-MB-231 and RIP3-MCF7/MDA-MB-231 cells. The cells were treated with 12.5 $\mu \mathrm{mol} / \mathrm{L}$ PTL for $48 \mathrm{~h}$ in the presence or absence of $10 \mathrm{mmol} / \mathrm{L} \mathrm{NAC}$. The cell growth inhibitory ratio was measured by MTT assay. Mean \pm SD. $n=3$. ${ }^{\mathrm{b}} \mathrm{P}<0.05,{ }^{\mathrm{c}} \mathrm{P}<0.01$.

changes and cell death ${ }^{[29]}$. Many studies have reported that ROS induce apoptosis in various cancer cells ${ }^{[30-32]}$. Our experiments demonstrated that RIP3 gene transfection enhanced the PTL-induced generation of intracellular ROS in MCF-7 and MDA-MB-231 cells. However, RIP3 was reported to enhance the activity of metabolism-related enzymes, which are essential for ROS production during TNF-a-induced necroptosis ${ }^{[6]}$. In our study, overexpressing RIP3 per se did not significantly increase the intracellular ROS level, and the exact mechanism by which RIP3 enhanced PTL-induced ROS accumulation requires further study.

\section{Conclusions}

Overexpression of RIP3 can sensitize human breast cancer MCF-7 and MDA-MB-231 cells to PTL, and the resulting intracellular ROS accumulation may contribute to the sensitizing effect. These results suggest that overexpression of RIP3 might be an alternative approach to circumventing the drug 
resistance of breast cancer.

\section{Acknowledgements}

This work was supported by the Anticancer Key Technologies R \& D Program of Tianjin, China (№ 12ZCDZSY16200).

\section{Author contribution}

Zhong-sheng TONG designed the study; Can LU and Li-yan ZHOU performed the research and wrote the paper; Xiaodong LIU contributed new reagents and analytical tools; Huijun XU and Xing-yu CHEN analyzed the data; and Yongsheng JIA and Yue CHEN revised the paper.

\section{References}

1 Sun X, Lee J, Navas T, Baldwin DT, Stewart TA, Dixit VM. RIP3, a novel apoptosis-inducing kinase. J Biol Chem 1999; 274: 16871-5.

2 Zhang D, Lin J, Han J. Receptor-interacting protein (RIP) kinase family. Cell Mol Immunol 2010; 7: 243-9.

3 Feng S, Yang Y, Mei Y, Ma L, Zhu DE, Hoti N, et al. Cleavage of RIP3 inactivates its caspase-independent apoptosis pathway by removal of kinase domain. Cell Signal 2007; 19: 2056-67.

4 Van Herreweghe F, Festjens N, Declercq W, Vandenabeele P. Tumor necrosis factor-mediated cell death: to break or to burst, that's the question. Cell Mol Life Sci 2010; 67: 1567-79.

5 Martinon F, Holler N, Richard C, Tschopp J. Activation of a proapoptotic amplification loop through inhibition of NF-kappaBdependent survival signals by caspase-mediated inactivation of RIP. FEBS Lett 2000; 468: 134-6.

6 Zhang DW, Shao J, Lin J, Zhang N, Lu BJ, Lin SC, et al. RIP3, an energy metabolism regulator that switches TNF-induced cell death from apoptosis to necrosis. Science 2009; 325: 332-6.

7 Declercq W, Vanden Berghe T, Vandenabeele P. RIP kinases at the crossroads of cell death and survival. Cell 2009; 138: 229-32.

8 Pozarowski P, Halicka DH, Darzynkiewicz Z. NF-kappaB inhibitor sesquiterpene parthenolide induces concurrently atypical apoptosis and cell necrosis: difficulties in identification of dead cells in such cultures. Cytometry A 2003; 54: 118-24.

9 Zhang S, Ong CN, Shen HM. Critical roles of intracellular thiols and calcium in parthenolide-induced apoptosis in human colorectal cancer cells. Cancer Lett 2004; 208: 143-53.

10 Kim JH, Liu L, Lee SO, Kim YT, You KR, Kim DG. Susceptibility of cholangiocarcinoma cells to parthenolide-induced apoptosis. Cancer Res 2005; 65: 6312-20.

11 Yip-Schneider MT, Nakshatri H, Sweeney CJ, Marshall MS, Wiebke EA, Schmidt CM. Parthenolide and sulindac cooperate to mediate growth suppression and inhibit the nuclear factor-kappa B pathway in pancreatic carcinoma cells. Mol Cancer Ther 2005; 4: 587-94.

12 Zhang S, Lin ZN, Yang CF, Shi X, Ong CN, Shen HM. Suppressed NFkappaB and sustained JNK activation contribute to the sensitization effect of parthenolide to TNF-alpha-induced apoptosis in human cancer cells. Carcinogenesis 2004; 25: 2191-9.

13 Wang W, Adachi M, Zhang R, Zhou J, Zhu D. A novel combination therapy with arsenic trioxide and parthenolide against pancreatic cancer cells. Pancreas 2009; 38: e114-23.

14 Wen J, You KR, Lee SY, Song CH, Kim DG. Oxidative stress-mediated apoptosis. The anticancer effect of the sesquiterpene lactone parthenolide. J Biol Chem 2002; 277: 38954-64.
15 Kwok BH, Koh B, Ndubuisi MI, Elofsson M, Crews CM. The antiinflammatory natural product parthenolide from the medicinal herb Feverfew directly binds to and inhibits IkappaB kinase. Chem Biol 2001; 8: 759-66.

16 Anderson KN, Bejcek BE. Parthenolide induces apoptosis in glioblastomas without affecting NF-kappaB. J Pharmacol Sci 2008; 106: 318-20.

17 Zunino SJ, Ducore JM, Storms DH. Parthenolide induces significant apoptosis and production of reactive oxygen species in high-risk pre-B leukemia cells. Cancer Lett 2007; 254: 119-27.

18 He JX, Wang YQ, Feng JM, Li JX, Xu L, Li XH, et al. Differential sensitivity of RIP3-proficient and deficient murine fibroblasts to camptothecin anticancer drugs. Acta Pharmacol Sin 2012; 33: 4268.

19 Pazdernik NJ, Donner DB, Goebl MG, Harrington MA. Mouse receptor interacting protein 3 does not contain a caspase-recruiting or a death domain but induces apoptosis and activates NF-kappaB. Mol Cell Biol 1999; 19: 6500-8.

20 Kasof GM, Prosser JC, Liu D, Lorenzi MV, Gomes BC. The RIP-like kinase, RIP3, induces apoptosis and NF-kappaB nuclear translocation and localizes to mitochondria. FEBS Lett 2000; 473: 285-91.

21 Yang Y, Ma J, Chen Y, Wu M. Nucleocytoplasmic shuttling of receptorinteracting protein 3 (RIP3): identification of novel nuclear export and import signals in RIP3. J Biol Chem 2004; 279: 38820-9.

22 Kurdi M, Booz GW. Evidence that IL-6-type cytokine signaling in cardiomyocytes is inhibited by oxidative stress: parthenolide targets JAK1 activation by generating ROS. J Cell Physiol 2007; 212: 424-31.

23 Sun Y, St Clair DK, Xu Y, Crooks PA, St Clair WH. A NADPH oxidasedependent redox signaling pathway mediates the selective radiosensitization effect of parthenolide in prostate cancer cells. Cancer Res 2010; 70: 2880-90.

24 Crack PJ, Taylor JM. Reactive oxygen species and the modulation of stroke. Free Radic Biol Med 2005; 38: 1433-44.

25 Yu PW, Huang BC, Shen M, Quast J, Chan E, Xu X, et al. Identification of RIP3, a RIP-like kinase that activates apoptosis and NFkappaB. Curr Biol 1999; 9: 539-42.

$26 \mathrm{Li} \mathrm{M}$, Feng S, Wu M. Multiple roles for nuclear localization signal (NLS, aa 442-472) of receptor interacting protein 3 (RIP3). Biochem Biophys Res Commun 2008; 372: 850-5.

27 Meylan E, Burns K, Hofmann K, Blancheteau V, Martinon F, Kelliher M, et al. RIP1 is an essential mediator of Toll-like receptor 3-induced NFkappa B activation. Nat Immunol 2004; 5: 503-7.

28 Dell'Agli M, Galli GV, Bosisio E, D'Ambrosio M. Inhibition of NF-kB and metalloproteinase- 9 expression and secretion by parthenolide derivatives. Bioorg Med Chem Lett 2009; 19: 1858-60.

29 ErmakG, Davies KJ. Calcium and oxidative stress: from cell signaling to cell death. Mol Immunol 2002; 38: 713-21.

30 Simbula G, Columbano A, Ledda-Columbano GM, Sanna L, Deidda M, Diana A, et al. Increased ROS generation and p53 activation in alphalipoic acid-induced apoptosis of hepatoma cells. Apoptosis 2007; 12: 113-23.

31 Reinecke F, Levanets O, Olivier Y, Louw R, Semete B, Grobler A, et al. Metallothionein isoform $2 \mathrm{~A}$ expression is inducible and protects against ROS-mediated cell death in rotenone-treated HeLa cells. Biochem J 2006; 395: 405-15.

32 Kang YH, Lee E, Choi MK, Ku JL, Kim SH, Park YG, et al. Role of reactive oxygen species in the induction of apoptosis by alphatocopheryl succinate. Int J Cancer 2004; 112: 385-92. 